\title{
Highly stereocontrolled synthesis of trans-enediynes via carbocupration of fluoroalkylated diynes
}

\author{
Tsutomu Konno*, Misato Kishi and Takashi Ishihara
}

\section{Letter}

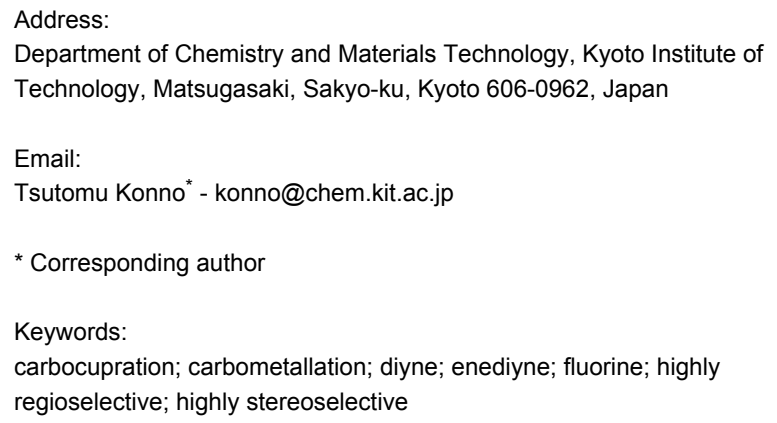

\begin{abstract}
Treatment of readily prepared (Z)-6-benzyloxy-1,1,1,2-tetrafluoro-6-methyl-2-hepten-4-yne with 1.5 equiv of LHMDS in -78 ${ }^{\circ} \mathrm{C}$ for $1 \mathrm{~h}$ gave the corresponding trifluoromethylated diyne in an excellent yield. This diyne was found to be a good substrate for the carbocupration with various higher-ordered cyanocuprates to give the corresponding vinylcuprates in a highly regio- and stereoselective manner. The in situ generated vinylcuprates could react very smoothly with an excess amount of iodine, the vinyl iodides being obtained in high yields. Thus-obtained iodides underwent a very smooth Sonogashira cross-coupling reaction to afford various trans-enediynes in high yields.
\end{abstract}

\section{Introduction}

trans-Enediynes (trans-hex-3-ene-1,5-diynes), as shown in Figure 1, are well-recognized as one of the most important

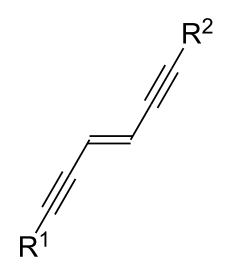

Figure 1: trans-Enediyne. building blocks because they are frequently utilized for the synthesis of $\pi$-conjugated polymers, which have attracted much attention in the fields of electronic and photonic materials science [1-3].

While numerous synthetic approaches to non-fluorinated transenediynes have been reported so far, there has been quite a limited number studies on the preparation of fluoroalkylated trans-enediynes [4-7], although the introduction of fluorine atom(s) into organic molecules very often changes their physical as well as chemical characteristics significantly, resulting in the discovery of new materials with unique physical properties [8-14]. 


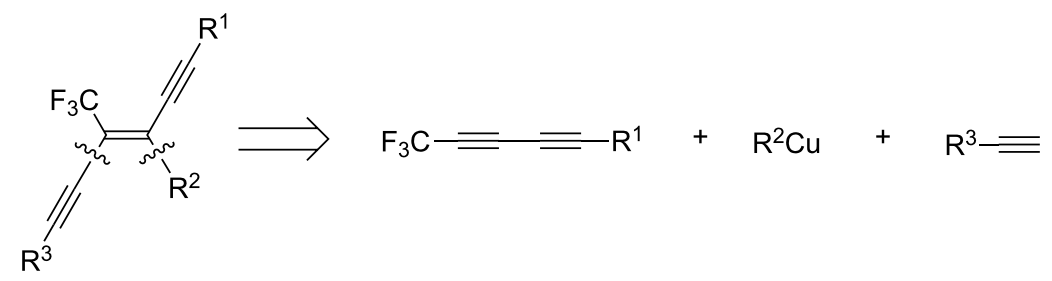

Scheme 1: Synthetic strategy for the preparation of trifluoromethylated diynes.

In this paper we report a convenient and efficient access to trifluoromethylated enediynes by the highly regio- and stereoselective carbocupration reaction of trifluoromethylated diyne with various organocuprates (Scheme 1).

\section{Results and Discussion}

Our initial studies began with the preparation of trifluoromethylated diyne derivatives [15-22]. Thus, treatment of 2,3,3,3-tetrafluoro-1-iodo-1-propene (1), which could be easily prepared from 2,2,3,3,3-pentafluoropropanol in three steps [23], with 1.2 equiv of terminal alkynes 2 and 1.5 equiv of $\mathrm{Et}_{3} \mathrm{~N}$ in the presence of $5 \mathrm{~mol} \%$ of $\mathrm{Pd}(\mathrm{OAc})_{2}$ and $10 \mathrm{~mol} \%$ each of $\mathrm{PPh}_{3}$ and $\mathrm{CuI}$ in DMF at room temperature for $24 \mathrm{~h}$, gave the corresponding Sonogashira cross-coupling products $\mathbf{3 a}-\mathbf{e}$ in good to high yields [24-26] (Scheme 2).

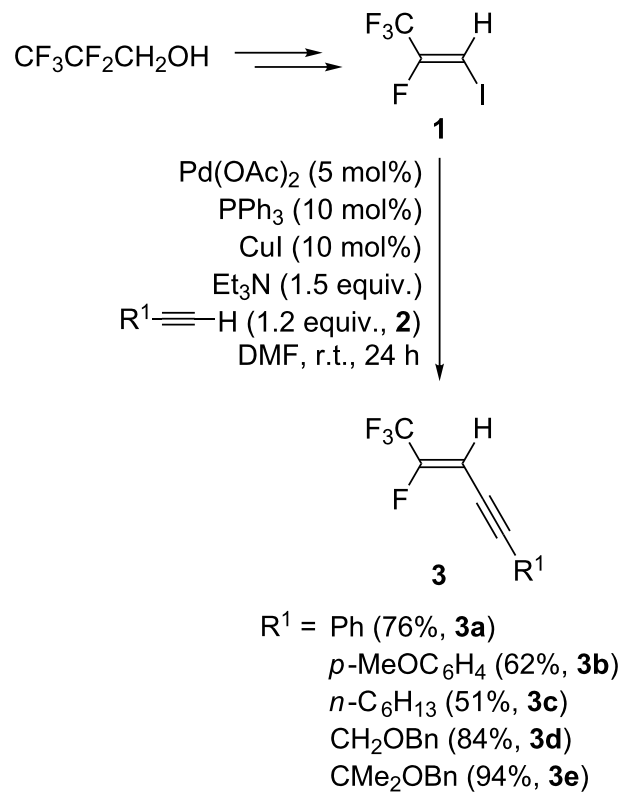

Scheme 2: Preparation of various enynes.

Subsequently, 3a was subjected to the usual $\beta$-elimination conditions according to the literature [23,27-29], i.e., treatment of 3a with 1.5 equiv of potassium tert-butoxide $(t$-BuOK) in THF at room temperature for $2 \mathrm{~h}$. Very surprisingly, the desired trifluoromethylated diyne $4 \mathbf{a}$ was not detected at all and the addition-elimination product $\mathbf{5} \mathbf{a}$ was obtained quantitatively. Therefore, we examined the reaction conditions for the $\beta$-elimination of 3a in detail (Table 1). As shown in Table 1, entries 2 and 3 , the reactions with $t$-BuOK in various solvents, such as 1,4-dioxane and ether, were found to be fruitless, leading to a quantitative formation of $5 \mathbf{a}$. Changing the base from $t$-BuOK to $\mathrm{KOH}$ brought about better results (Table 1, entries 4-6). Thus, the reaction with 1.5 equiv of $\mathrm{KOH}$ at the reflux temperature of THF produced the desired diyne $\mathbf{4 a}$ in ca. $10 \%$, while no desired product was given at room temperature. On the other hand, a dramatic change could be observed when the amide bases were used. The use of lithium diisopropylamide (LDA) in THF at $-78{ }^{\circ} \mathrm{C}$ for $2 \mathrm{~h}$ resulted in a significant increase of the yield from $10 \%$ to $46 \%$ (Table 1, entry 7 ). Switching LDA into lithium hexamethyldisilazide (LHMDS) led to a further improvement of the yield (Table 1, entry 8). Finally, the best yield was obtained when the reaction was carried out in THF at $-78^{\circ} \mathrm{C}$ for $1 \mathrm{~h}$ by using LHMDS. In this case the desired diyne 4a was generated in $74 \%{ }^{19} \mathrm{~F}$ NMR yield as a sole product. Unfortunately, 4a was found to be somewhat thermally unstable, and a partial decomposition was observed in silica-gel column chromatography, $\mathbf{4 a}$ being isolated in very low yield. Additionally, such a partial decomposition of $\mathbf{4 a}$ was also observed even when 4a was kept in a freezer.

With the thus-obtained optimum reaction conditions, we next investigated the $\beta$-elimination reaction of various enynes as described in Table 2. As shown in Table 2, entry 2, changing a phenyl group into an anisyl group in $\mathrm{R}^{1}$ resulted in a significant increase of the yield from $74 \%$ to a quantitative yield. In this case, it was found that $\mathbf{4 b}$ was slightly thermally stable, compared to $4 \mathbf{a}$, while it could not be isolated in a pure form. In the case of the enyne having an $n-\mathrm{C}_{6} \mathrm{H}_{13}$ group as $\mathrm{R}^{1}$, on the other hand, the starting material was not completely consumed, and an inseparable mixture of the desired diyne $4 \mathbf{c}$ and the enyne 3c was given (Table 2, entry 3 ). In addition, the reaction proceeded very sluggishly in the enyne having $\mathrm{CH}_{2} \mathrm{OBn}$ as $\mathrm{R}^{1}$, 
Table 1: Investigation of the reaction conditions.

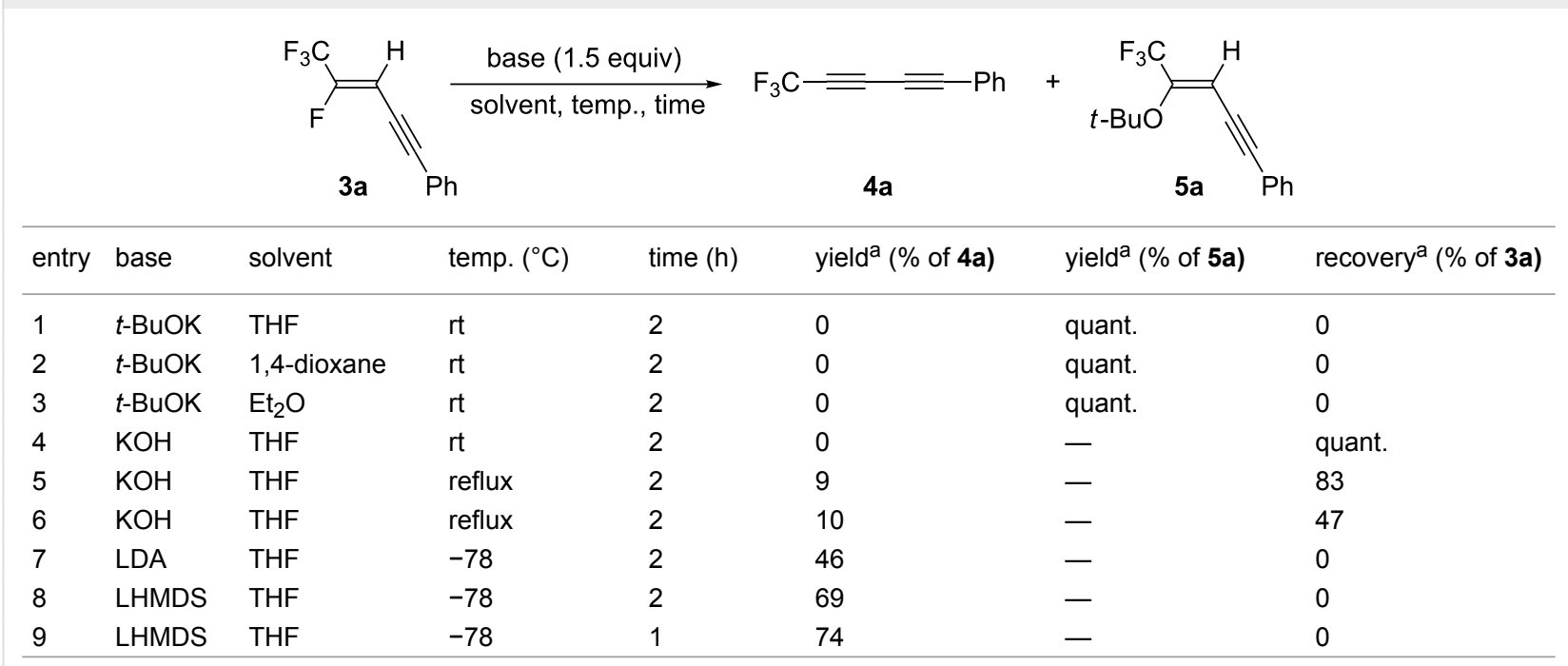

aDetermined by ${ }^{19} \mathrm{~F}$ NMR.

Table 2: $\beta$-Elimination of various enynes.

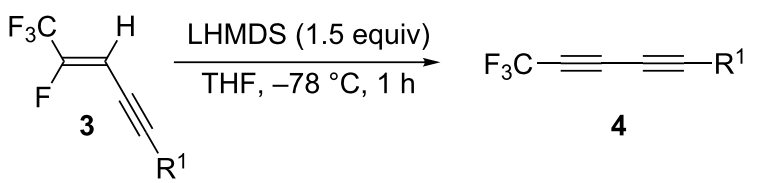

\begin{tabular}{llll}
\hline entry & $\mathrm{R}^{1}$ & yield ${ }^{\mathrm{a}}(\%$ of 4$)$ & recovery $^{\mathrm{a}}(/ \%$ of 3) \\
\hline 1 & $\mathrm{Ph} \mathrm{(a)}$ & 74 & 0 \\
2 & $p-\mathrm{MeOC}_{6} \mathrm{H}_{4}(\mathbf{b})$ & quant. & 0 \\
$3^{\mathrm{b}}$ & $n-\mathrm{C}_{6} \mathrm{H}_{13}(\mathbf{c})$ & 48 & 35 \\
4 & $\mathrm{CH}_{2} \mathrm{OBn}(\mathbf{d})$ & 3 & 13 \\
5 & $\mathrm{CMe}_{2} \mathrm{OBn}(\mathbf{e})$ & quant. & 0 \\
\hline
\end{tabular}

adermined by ${ }^{19} \mathrm{~F}$ NMR. Value in parentheses is of isolated yield. ${ }^{\mathrm{b}}$ Carried out for $24 \mathrm{~h}$.

and neither $\mathbf{3 d}$ nor $\mathbf{4 d}$ could be obtained in high yields (Table 2, entry 4). Interestingly, the enyne $\mathbf{3 e}$ having a $\mathrm{CMe}_{2} \mathrm{OBn}$ group as $\mathrm{R}^{1}$ was found to be a good substrate, the desired diyne $4 \mathbf{e}$ being obtained quantitatively (Table 2 , entry 5 ). Additionally, 4e was so thermally stable that it could be obtained in $95 \%$ isolated yield after the silica-gel column chromatography.

With the substrate $4 \mathbf{e}$ in hand, our interest was next directed toward the carbocupration reaction of $4 \mathbf{e}$. First of all, we attempted the investigation of the reaction conditions for the carbocupration reaction of $\mathbf{4 e}$, as described in Table 3. Thus, treatment of $4 \mathrm{e}$ with 1.2 equiv of higher-ordered cyanocuprate $(n-\mathrm{Bu})_{2} \mathrm{CuLi} \cdot \mathrm{LiCN}$, which was prepared from $\mathrm{CuCN}$ and 2 equiv of $n$-BuLi, at $-78^{\circ} \mathrm{C}$ for $2 \mathrm{~h}$, followed by quenching the reaction with saturated aqueous $\mathrm{NH}_{4} \mathrm{Cl}$, gave the corresponding carbocupration product 5 in $46 \%$ yield as a sole product (it is well known that the carbocupration reaction of fluoroalkylated alkynes with cuprates proceeds in a highly cis-selective manner $[30,31])$, together with a slight recovery of the starting material (Table 3 , entry 1 ). In this case, the reaction proceeded in a highly regio- and stereoselective manner and the other isomers 6-12 were not detected at all (Figure 2). It was especially noteworthy that only the triple bond possessing a $\mathrm{CF}_{3}$ group, not the triple bond having a $\mathrm{CMe}_{2} \mathrm{OBn}$ group, was subjected to the carbocupration reaction. As shown in Table 3, entry 2, raising the reaction temperature from -78 to $-45{ }^{\circ} \mathrm{C}$ led to a significant increase in the yield. We also examined the reaction with the cuprate prepared from Grignard reagent, $n$ - BuMgBr. As 
Table 3: Investigation of the reaction conditions in carbocupration.

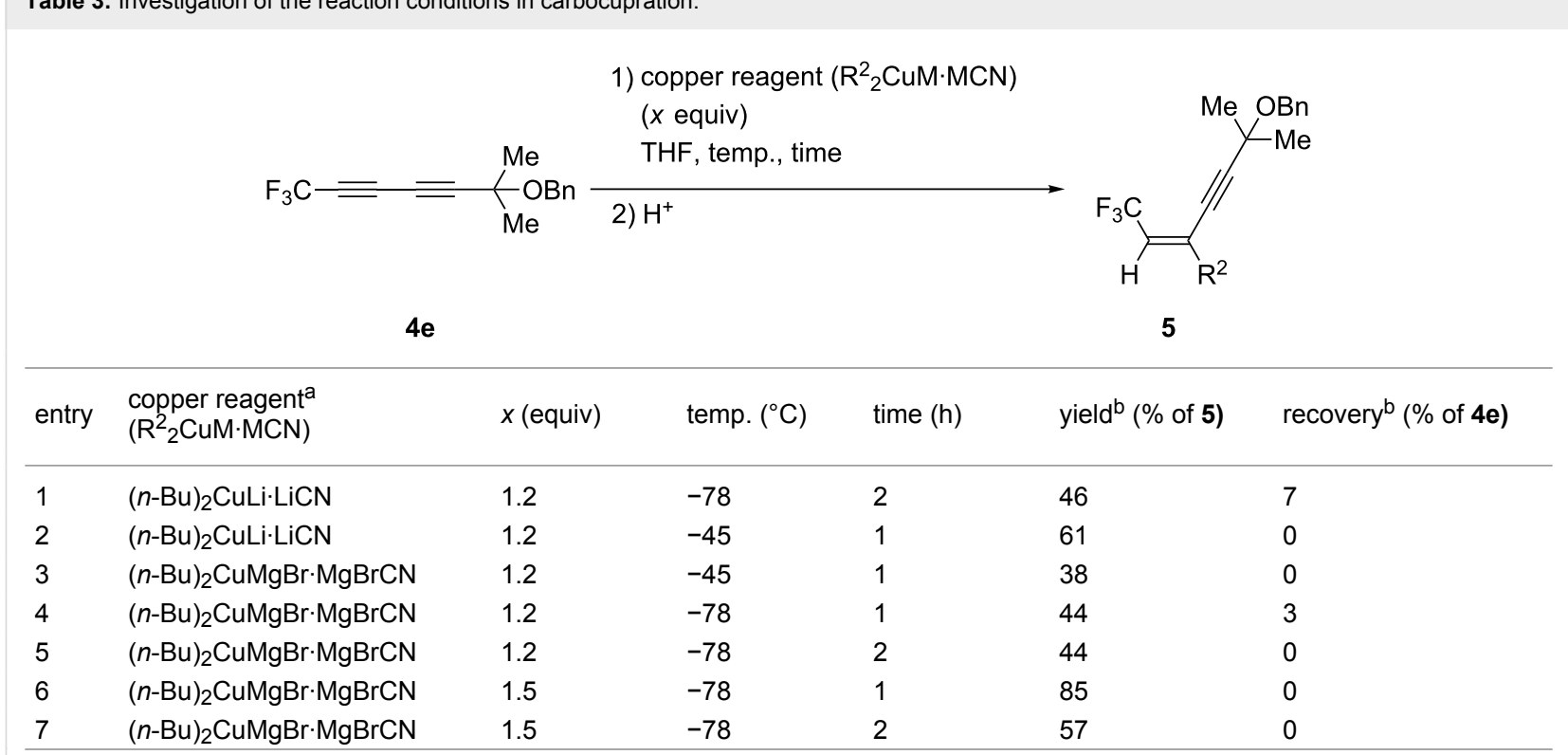

${ }^{a}$ Copper reagents were prepared from 1 equiv of $\mathrm{CuCN}$ and 2 equiv of $\mathrm{R}^{2} \mathrm{Li}$ or $\mathrm{R}^{2} \mathrm{MgBr}$. ${ }^{\mathrm{b}}$ Determined by ${ }^{19} \mathrm{~F} N \mathrm{NR}$.

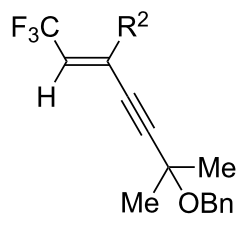

6

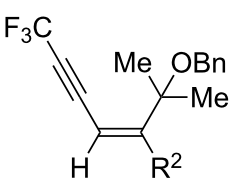

9<smiles>[R]/C(=C/C#CC([Y6])([18OH])[18OH])C(F)(F)F</smiles>

7

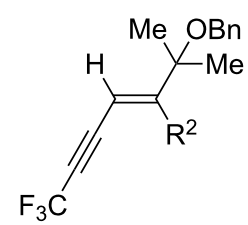

10<smiles>[R]/C(C#CC(F)(F)F)=C\C(C)(C)Br</smiles>

Figure 2: Regio- and stereoisomers.

summarised in Table 3, entries 3-5, a significant decrease of the yield was observed when the reaction was performed by using 1.2 equiv of cuprate. Very interestingly, the use of 1.5 equiv of the higher-ordered cyanocuprate realized the most satisfactory result, the desired product being obtained in $85 \%$ yield, though the yield was somewhat eroded in the reaction for $2 \mathrm{~h}$.

With the optimum reaction conditions in hand, we next investigated the carbocupration reaction by using various copper reagents. In all cases, iodine was employed as an electrophile instead of aqueous $\mathrm{NH}_{4} \mathrm{Cl}$. The results are summarised in Table 4. As shown in Table 4, entries 1 and 2, $(n-\mathrm{Bu})_{2} \mathrm{CuLi} \cdot \mathrm{LiCN}$ and $\mathrm{Me}_{2} \mathrm{CuLi} \cdot \mathrm{LiCN}$ could participate in the reaction to give the corresponding iodide 13a,b in good yields. Furthermore, the cuprates prepared from alkyl Grignard reagents, such as $n-\mathrm{Bu}, \mathrm{Me}$, and cyclohexylmagnesium bromide, reacted smoothly (Table 4, entries 3-5). Switching the cuprate from dialkylcuprate into diarylcuprate did not bring about any influence on the yields at all (Table 4, entries 6 and 7).

A proposed reaction mechanism is outlined in Scheme 3. Based on the accumulated studies on the chemistry of fluoroalkylated alkynes, it appears possible that the copper reagent coordinates to the triple bond proximate to the $\mathrm{CF}_{3}$ group (Int-A), rather than the alternative one (Int-B), due to high reactivity of the fluoroalkylated alkyne. Then, $\mathrm{Cu}^{\mathrm{I}}$ adds oxidatively to the alkyne to form the intermediate Int-C, not Int-D. Since a $\mathrm{CF}_{3}$ group has a very strong electron-withdrawing ability, the $\mathrm{CF}_{3} \mathrm{C}^{\alpha}-\mathrm{Cu}^{\mathrm{III}}$ bond may be stronger than $\mathrm{Cu}^{\mathrm{III}}-\mathrm{C}^{\beta}$. (In the hydrometalation and the carbometalation reaction of fluoroalkylated alkynes, the same regioselectivity was observed [32-35].) Accordingly, a transfer of the $\mathrm{R}^{2}$ group on $\mathrm{Cu}^{\mathrm{III}}$ to the olefinic 
Table 4: Carbocupration with various cuprates

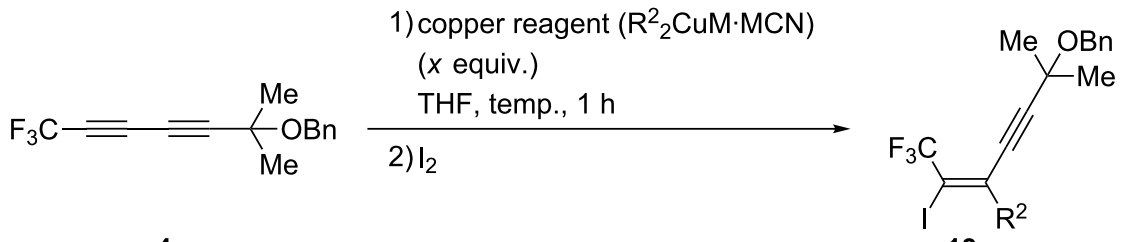

$4 \mathrm{e}$

13

\begin{tabular}{|c|c|c|c|c|c|}
\hline entry & $\begin{array}{l}\text { copper reagent }^{a} \\
\left(\mathrm{R}_{2}^{2} \mathrm{CuM} \cdot \mathrm{MCN}\right)\end{array}$ & $x$ (equiv) & temp. $\left({ }^{\circ} \mathrm{C}\right)$ & product & yield $^{\mathrm{b}}(\%$ of 13 ) \\
\hline 1 & $(n-\mathrm{Bu})_{2} \mathrm{CuLi} \cdot \mathrm{LiCN}$ & 1.2 & -45 & $13 a$ & 54 \\
\hline 2 & $\mathrm{Me}_{2} \mathrm{CuLi} \cdot \mathrm{LiCN}$ & 1.2 & -45 & $13 b$ & 55 \\
\hline 3 & $(n-\mathrm{Bu})_{2} \mathrm{CuMgBr} \cdot \mathrm{MgBrCN}$ & 1.5 & -78 & $13 a$ & 60 \\
\hline 4 & $\mathrm{Me}_{2} \mathrm{CuMgBr} \cdot \mathrm{MgBrCN}$ & 1.5 & -78 & $13 b$ & 59 \\
\hline 5 & $\mathrm{Cy}_{2} \mathrm{CuMgBr} \cdot \mathrm{MgBrCN}$ & 1.5 & -78 & $13 c$ & 44 \\
\hline 6 & $\mathrm{Ph}_{2} \mathrm{CuMgBr} \cdot \mathrm{MgBrCN}$ & 1.5 & -78 & $13 d$ & 55 \\
\hline 7 & $\left(p-\mathrm{MeOC}_{6} \mathrm{H}_{4}\right)_{2} \mathrm{CuMgBr} \cdot \mathrm{MgBrCN}$ & 1.5 & -78 & $13 e$ & 49 \\
\hline
\end{tabular}

${ }^{a}$ Copper reagents were prepared from 1 equiv of $\mathrm{CuCN}$ and 2 equiv of $\mathrm{R}^{2} \mathrm{Li}$ or $\mathrm{R}^{2} \mathrm{MgBr}$. ${ }^{\mathrm{b}}$ Isolated yield.
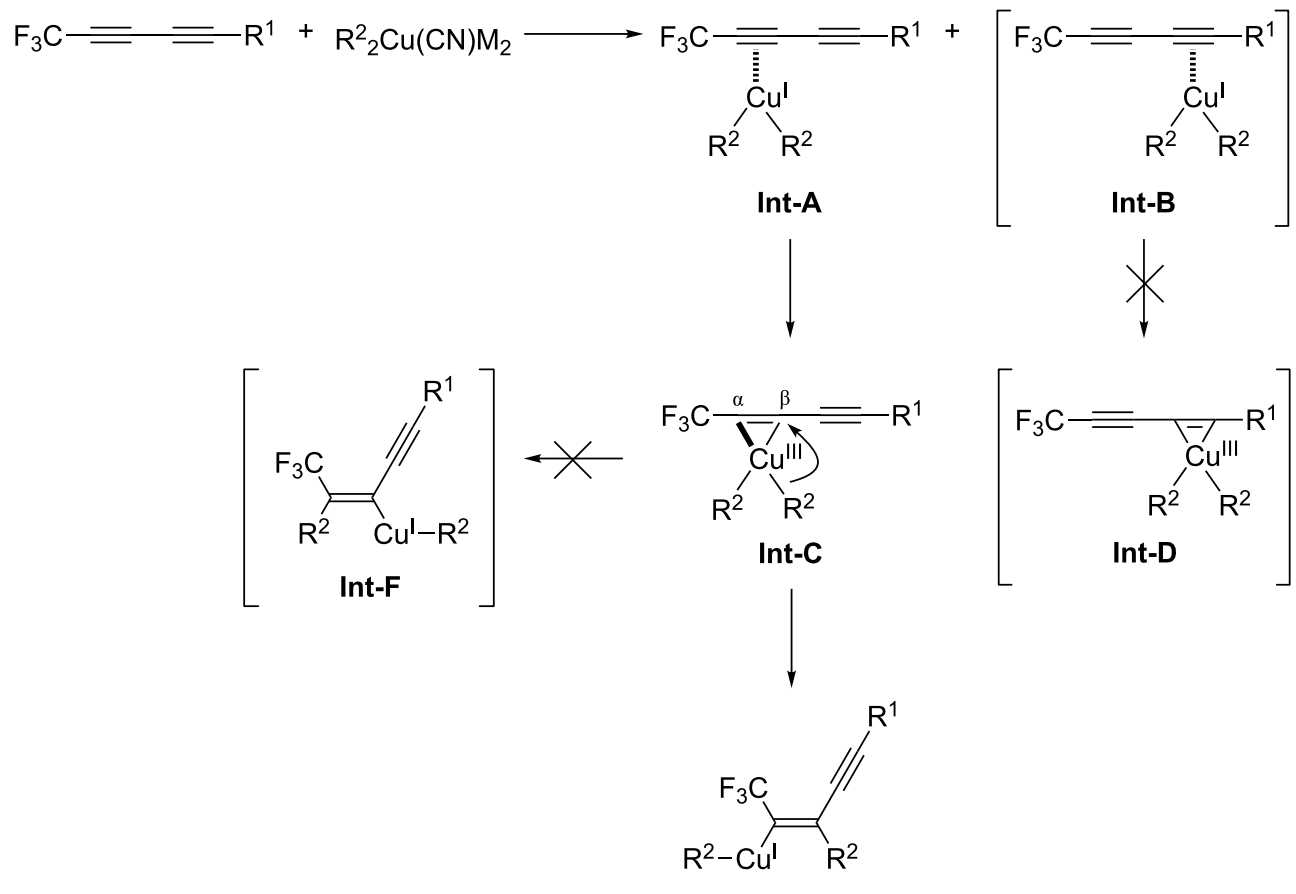

Int-E

Scheme 3: A proposed reaction mechanism.

carbon distal to a $\mathrm{CF}_{3}$ group may take place preferably, with vinylcopper intermediate Int-E, not Int-F, being produced exclusively. As a result, vinyl iodide $\mathbf{1 3}$ can be given in a highly regio- and stereoselective manner.
Finally, we attempted the Sonogashira cross-coupling reaction of the obtained iodide 13a (Scheme 4). Thus, treatment of 13a with 1.2 equiv of terminal alkynes and 40 equiv of $\mathrm{Et}_{3} \mathrm{~N}$ in the presence of $10 \mathrm{~mol} \%$ each of $\mathrm{Pd}\left(\mathrm{PPh}_{3}\right)_{4}$ and $\mathrm{CuI}$ in THF at 


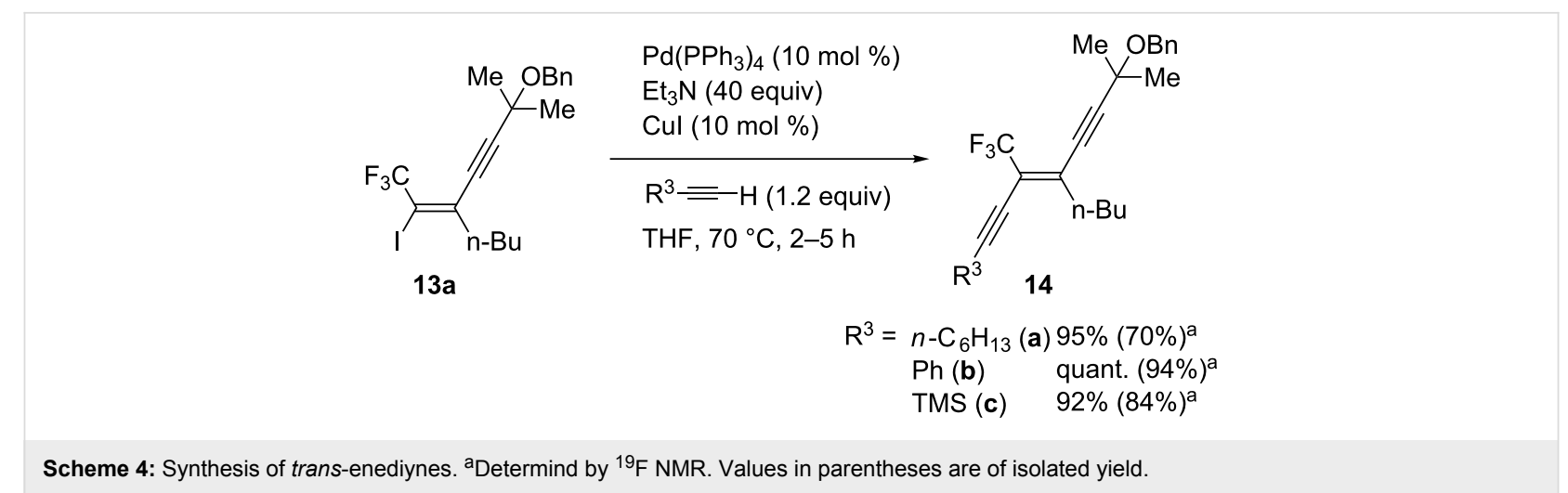

$70{ }^{\circ} \mathrm{C}$ for $2-5 \mathrm{~h}$ gave the corresponding enediynes $14 \mathbf{a}-\mathbf{c}$ in high to excellent yields. In all cases, other stereoisomers were not detected at all and $\mathbf{1 4 a}-\mathbf{c}$ were generated as the sole products in a pure form.

\section{Conclusion}

In summary, we have established a convenient as well as efficient access to the trifluoromethylated diyne by Sonogashira cross-coupling reaction of readily accessible 2,3,3,3-tetrafluoro1-iodo-1-propene (1) and the following HF elimination reaction. The thus-obtained $\mathrm{CF}_{3}$-enediyne could participate in the carbocupration with various higher-ordered cyanocuprates very well to give the corresponding vinyliodides in good yields. Finally, the thus-obtained iodide underwent a smooth Sonogashira cross-coupling reaction to afford the various desired trans-enediyne derivatives in high yields.

\section{Supporting Information}

\section{Supporting Information File 1}

Experimental, characterization details, and NMR spectra of synthesized compounds, 4e, 13a-e, and 14a-c.

[http://www.beilstein-journals.org/bjoc/content/ supplementary/1860-5397-8-249-S1.pdf]

\section{Acknowledgements}

The authors thank Daikin Industries, Ltd. for supplying 2,2,3,3,3-pentafluoropropanol.

\section{References}

1. Liu, Y.; Gao, H. Org. Lett. 2006, 8, 309-311. doi:10.1021/ol052706+

2. Nielsen, M. B.; Diederich, F. Chem. Rev. 2005, 105, 1837-1868. doi:10.1021/cr9903353

3. Martin, R. E.; Diederich, F. Angew. Chem., Int. Ed. 1999, 38, 1350-1377.

doi:10.1002/(SICI)1521-3773(19990517)38:10<1350::AID-ANIE1350>3 .0.CO;2-6
4. Jeon, H. H.; Son, J. B.; Choi, J. H.; Jeong, I. H. Tetrahedron Lett. 2007, 48, 627-631. doi:10.1016/j.tetlet.2006.11.111

5. Yamada, S.; Konno, T.; Ishihara, T.; Yamanaka, H. J. Fluorine Chem. 2005, 126, 125-133. doi:10.1016/j.jfluchem.2004.10.047

6. Shimizu, M.; Fujimoto, T.; Liu, X.; Minezaki, H.; Hata, T.; Hiyama, T. Tetrahedron 2003, 59, 9811-9823. doi:10.1016/j.tet.2003.09.098

7. Shimizu, M.; Fujimoto, T.; Minezaki, H.; Hata, T.; Hiyama, T. J. Am. Chem. Soc. 2001, 123, 6947-6948. doi:10.1021/ja016077k

8. O'Hagan, D. Chem. Soc. Rev. 2008, 37, 308-319. doi:10.1039/b711844a

9. Bégué, J.-P.; Bonnet-Delpon, D. J. Fluorine Chem. 2006, 127, 992-1012. doi:10.1016/j.jfluchem.2006.05.006

10. Yamamoto, S.; Matsuda, K.; Irie, M. Org. Lett. 2003, 5, 1769-1772. doi:10.1021/ol034440h

11. Kaieda, T.; Kobatake, S.; Miyasaka, H.; Murakami, M.; Iwai, N.; Nagata, Y.; Itaya, A.; Irie, M. J. Am. Chem. Soc. 2002, 124, 2015-2024. doi:10.1021/ja0115722

12. Irie, M. Chem. Rev. 2000, 100, 1685-1716. doi:10.1021/cr980069d

13. Hiyama, T., Ed. Organofluorine Compounds, Chemistry and Applications; Springer: New York, NY, 2000.

14. Smart, B. E., Ed. Fluorine Chemistry. Chem. Rev. 1996, 96, 1555-1824. doi:10.1021/cr960075e

15. Robert-Estelrich, A.; Castella-Martínez, M.; López-Calahorra, F. Tetrahedron 2004, 60, 4289-4293. doi:10.1016/j.tet.2004.03.053

16. Klyuchinskii, S. A.; Zavgorodnii, V. S.; Petrov, A. A. Zh. Obshch. Khim. 1989, 59, 1190-1191.

17. Turbanova, E. S.; Denisov, V. R.; Petrov, A. A. Zh. Org. Khim. 1988, 24, 2447-2448.

18. Stepanova, N. P.; Kuz'mina, N. Y.; Turbanova, E. S.; Petrov, M. L. Zh. Org. Khim. 1986, 22, 1857-1861.

19. Turbanova, E. S.; Orlova, N. A.; Stepanova, N. P.; Petrov, A. A. Zh. Org. Khim. 1985, 21, 974-979.

20. Stepanova, N. P.; Orlova, N. A.; Galishev, V. A.; Turbanova, E. S.; Petrov, A. A. Zh. Org. Khim. 1985, 21, 979-983.

21. Turbanova, E. S.; Stepanova, N. P.; Lebedev, V. B.; Galishev, V. A.; Petrov, A. A. Zh. Org. Khim. 1983, 19, 221-222.

22. Turbanova, E. S.; Orlova, N. A.; Ratsino, E. V.; Sokolov, L. B. Zh. Org. Khim. 1981, 17, 736-740.

23. Konno, T.; Chae, J.; Kanda, M.; Nagai, G.; Tamura, K.; Ishihara, T.; Yamanaka, H. Tetrahedron 2003, 59, 7571-7580. doi:10.1016/S0040-4020(03)01199-2

24. Chinchilla, R.; Nájera, C. Chem. Soc. Rev. 2011, 40, 5084-5121. doi:10.1039/c1cs15071e

25. Chinchilla, R.; Nájera, C. Chem. Rev. 2007, 107, 874-922. doi:10.1021/cr050992x 
26. Doucet, H.; Hierso, J.-C. Angew. Chem., Int. Ed. 2007, 46, 834-871. doi:10.1002/anie.200602761

27. Chambers, R. D.; Roche, A. J. J. Fluorine Chem. 1996, 79, 121-124. doi:10.1016/S0022-1139(96)03447-1

28. Hiyama, T.; Sato, K.; Fujita, M. Bull. Chem. Soc. Jpn. 1989, 62, 1352-1354. doi:10.1246/bcsj.62.1352

29. Meazza, G.; Capuzzi, L.; Piccardi, P. Synthesis 1989, 331-334. doi:10.1055/s-1989-27247

30. Konno, T.; Daitoh, T.; Noiri, A.; Chae, J.; Ishihara, T.; Yamanaka, H. Tetrahedron 2005, 61, 9391-9404. doi:10.1016/j.tet.2005.07.022

31. Konno, T.; Daitoh, T.; Noiri, A.; Chae, J.; Ishihara, T.; Yamanaka, H. Org. Lett. 2004, 6, 933-936. doi:10.1021/ol036440n

32. Konno, T.; Taku, K.; Yamada, S.; Moriyasu, K.; Ishihara, T. Org. Biomol. Chem. 2009, 7, 1167-1170. doi:10.1039/b819476a

33. Konno, T.; Ishihara, T. A New Aspect of Fluoroalkylated Acetylenes: Synthesis and Applications-Hydrometallation and Carbometallation. In Fluorine-Containing Synthons; Soloshonok, V. A., Ed.; ACS Publications: Washington, DC, 2005; pp 190-203. doi:10.1021/bk-2005-0911.ch009

34. Konno, T.; Chae, J.; Tanaka, T.; Ishihara, T.; Yamanaka, H. J. Fluorine Chem. 2006, 127, 36-43. doi:10.1016/j.jfluchem.2005.09.015

35. Konno, T.; Chae, J.; Tanaka, T.; Ishihara, T.; Yamanaka, H. Chem. Commun. 2004, 690-691. doi:10.1039/b316065c

\section{License and Terms}

This is an Open Access article under the terms of the Creative Commons Attribution License

(http://creativecommons.org/licenses/by/2.0), which permits unrestricted use, distribution, and reproduction in any medium, provided the original work is properly cited.

The license is subject to the Beilstein Journal of Organic Chemistry terms and conditions:

(http://www.beilstein-journals.org/bjoc)

The definitive version of this article is the electronic one which can be found at: doi:10.3762/bjoc.8.249 